\title{
Creep Properties of Expansive Soils under Triaxial Drained Conditions and its Nonlinear Constitutive Model
}

\author{
Jingjing $\mathrm{Li}^{1 *}$, Lingwei Kong ${ }^{2,3}$ \\ ${ }^{1}$ School of Civil Engineering, Hubei Polytechnic University, Huangshi, 435003, China \\ ${ }^{2}$ State Key Laboratory of Geomechanics and Geotechnical Engineering, Institute of Rock and Soil Mechanics, Chinese Academy of \\ Sciences, Wuhan, Hubei 430071, China \\ ${ }^{3}$ University of Chinese Academy of Sciences, Beijing, 100049, China \\ * Corresponding author, e-mail: 206073@hbpu.edu.cn
}

Received: 22 April 2021, Accepted: 30 August 2021, Published online: 08 September 2021

\begin{abstract}
The creep behaviors of expansive soils play an important role in landslide prediction and long-term stability analysis. In this paper, triaxial drained compression creep tests of expansive soils were conducted on the improved stress-controlled triaxial apparatus. The test results show that only transient deformation and attenuation creep occur with low deviator stress, and the increment of axial strain increases exponentially with deviator stress increasing; while deviator stress reaches a certain value, attenuation creep, steady creep and accelerated creep all occur in a creep curve. Meanwhile, the volumetric strain presents the shear shrinkage characteristic at the initial stage of loading, and the shear shrinkage is small. With the extension of loading time, the volumetric strain gradually varies from shear contraction to dilatancy. When entering the accelerated creep stage, the development rate of volumetric strain increases sharply. Besides, isochronous stress-strain curves of expansive soils indicate that their creep process possesses nonlinear characteristics, and the nonlinear degree is related to creep time and stress level. Imitating the empirical formula of cyclic cumulative deformation of clay, a new nonlinear creep model is presented, which may well describe the creep property of expansive soils. Furthermore, critical failure stress could be obtained based on the proposed creep model. The ratio of the critical failure stress to conventional shear failure stress ranges from $70 \%$ to $80 \%$, with average of $75.56 \%$, therefore, critical failure stress may be estimated by conventional triaxial tests with the margin of error $5.5 \%$ within.
\end{abstract}

\section{Keywords}

expansive soil, triaxial creep test, nonlinearity, creep model, critical failure stress

\section{Introduction}

Expansive soils are widely distributed in more than 40 countries from six continents and are encountered in more than 20 provinces and cities in China with an area of $100,000 \mathrm{~km}^{2}$. The slide often occurs on the expansive soil slope, which is generally characterized by time-dependent properties as chronicity and gradualness [1]. The long-term mechanical behavior of its slope stability may closely relate to creep, so that it is necessary to study the creep property of expansive soils.

Researches on the creep properties of soil mainly cover creep tests and creep constitutive models. In the aspect of soil creep tests, the researches have been conducted on a variety of soils, including coarse-grained soil [2], loess [3-5], calcareous sand [6, 7], marine soil [8], frozen soil [9-12]. Abundant literatures about creep characteristics of soft soil [13-17] have been reported due to its obvious creep characteristics with high moisture content and high compressibility. Whereas, as a kind of cohesive soil, little attention has been paid on the creep characteristics of expansive soils, and the studies concerned mainly based on consolidation creep tests [18] and direct shear creep tests [19], rarely on triaxial creep tests. Ning et al. [20] conducted triaxial undrained creep tests on the expansive soil of Nanning, China, to study its nonlinear creep characteristics. However, they used remolded soil samples that could not reflect the influence of nature structure.

Researches on soil creep model are abundant. The macroscopic creep models mainly include empirical model, general rheological theoretical model and viscoelastoplastic model. The empirical model is easy to be accepted and 
used by engineering designers for it is intuitive and simple, so it has always been a research topic of rheology in engineering. However, the universality of empirical models is generally poor. Singh-Mitchell Fuction [21] and Mesri Fuction [22] are widely used empirical models that based on exponential function and hyperbolic function, respectively. Li et al. [23] found that the modified Mesri creep function could only be used to describe the creep behavior of clay when the deviator stress was less than the failure deviator stress, so they developed cubic polynomial to describe the creep behavior when the deviator stress was equal to the failure deviator stress. Zhou et al. [5] established two empirical models to describe the creep characteristics of loess, but both of them had limitations in their application scope. It can be seen that the previous empirical model is not universal. Therefore, it is necessary to further establish a more versatile empirical model for engineering.

In this paper, triaxial drainage creep tests were conducted on typical expansive soils selected in Nanyang Basin, Henan province, China, to study the evolution law of axial deformation and volumetric strain with loading time under constant pressure. On the basis of creep test results, a nonlinear creep model with good universality was established to describe the creep characteristics of expansive soils under triaxial stress.

\section{Test scheme}

\subsection{Properties of test soils}

The test soils were taken from an expansive soil slope with about $4.0 \mathrm{~m}$ in height at the Nei-Deng expressway in Nanyang Basin, Henan province, China, by the method of pit exploration. The test soils are in hard plastic-hard state with reddish-brown color. The test results of basic physical property measurement and the X-ray diffraction analysis of the expansive soil are shown in Tables 1-3. From the results above, it can be seen that the samples have high liquid and plastic limits, $44.8 \%$ of clay particle content and $62 \%$ of free swell ratio. The studied soils are mainly composed of montmorillonite and chlorite with small amount of illite and kaolinte, whereas the non-clay minerals include quartz and feldspar. Moreover, the samples have a similar swelling to the medium swelling grade expansive soil.

Fig. 1 shows the compression curve of the expansive soil. Base on the compression curve, the Cassagrande method was adopted to determine the preconsolidation pressure of the expansive soil sample. Its preconsolidation pressure $p_{c}$ was around $160 \mathrm{kPa}$, while its current overburden pressure was about $80 \mathrm{kPa}$. Therefore, the expansive soil was overconsolidated.
Table 1 Physical property indexes of the expansive soil

\begin{tabular}{ccccccc}
\hline$\omega / \%$ & $\gamma / \mathrm{kN} \cdot \mathrm{m}^{-3}$ & $G_{s}$ & $S_{r} \%$ & $\delta_{e f} / \%$ & $\omega_{P} / \%$ & $I_{p} / \%$ \\
24.7 & 19.8 & 2.71 & 95.3 & 62 & 26.2 & 29.2 \\
\hline
\end{tabular}

Note: $\omega$ - Water Content; $\gamma$ - Unit weight; $G_{s}$ - Specific gravity; $S_{r}$ Saturation; $\delta_{e f}$ - Free swell ratio; $\omega_{P}$ - Plastic limit; $I_{p}$ - Plasticity index.

Table 2 Grain size distribution of the expansive soil

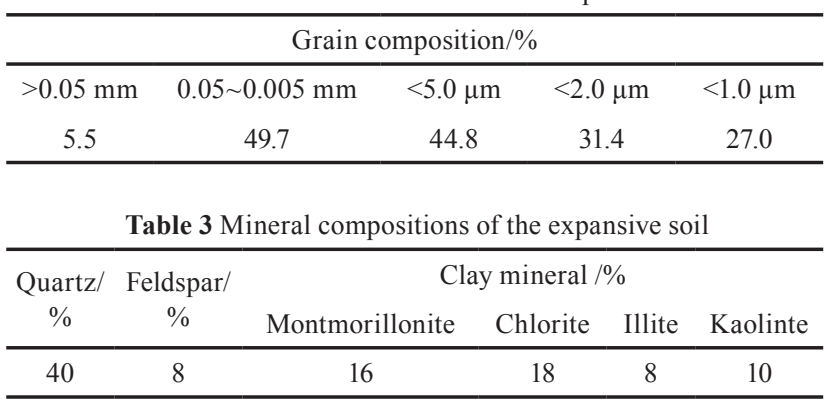

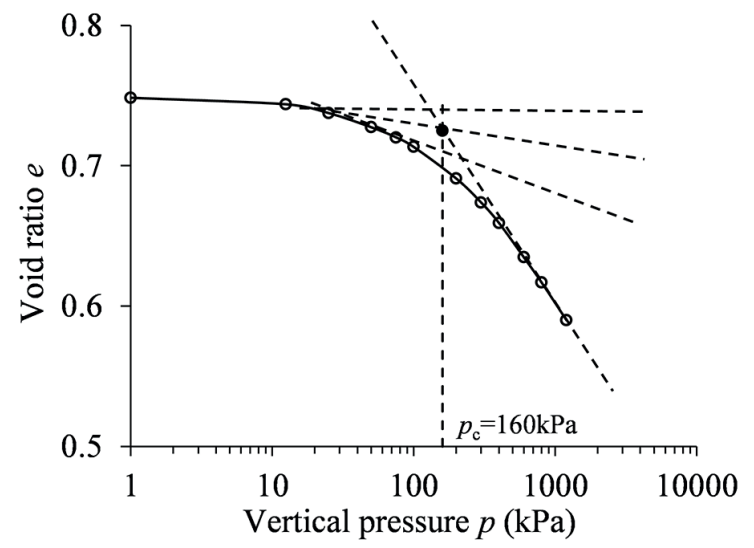

Fig. 1 Compression curve of the expansive soil

\subsection{Test equipment}

The test equipment is modified based on the strain-controlled triaxial apparatus SJ-1AJ. As shown in Fig. 2, the loading systems of confining pressure and back pressure, and monitoring systems of pore water pressure and volume change remain unchanged, while the axial loading system is changed from the strain-controlled type to the stress-controlled one applied by the weight. Monitoring systems were installed in front of the volume variable tube and dial indicator, respectively, to realize the continuity of collected data.

\subsection{Test methods}

Due to the long duration of triaxial creep test and the limited number of expansive soil samples, in order to avoid the inaccuracy of the test results caused by the discreteness and non-uniformity of the expansive soil samples, the triaxial creep test was carried out by grading loading.

The undisturbed expansive soil samples with $50 \mathrm{~mm}$ in diameter and $100 \mathrm{~mm}$ in height were used for test. The first step of the test was to determine the failure deviator stress 


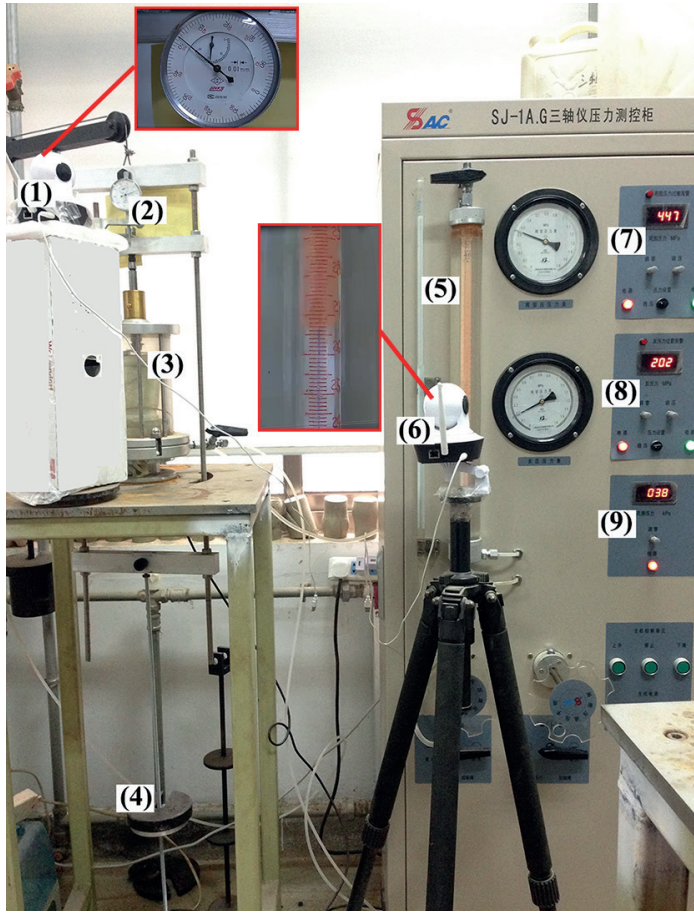

Fig. 2 Stress-controlled triaxial apparatus (1) Axial displacement monitoring system, (2) Axial displacement dial indicator, (3) Triaxial

chamber, (4) Axial loading system, (5) Volume variable tube, (6)

Monitoring system of volume change, (7) Loading system of confining pressure, (8) Loading system of back pressure, (9) Monitoring system of pore-water pressure

$\left(q_{f}=\left(\sigma_{1}-\sigma_{3}\right)_{f}\right)$ of the saturated soil specimens under different confining pressures. The $q_{f}$ was determined by consolidated-drained triaxial shear (CD) test with a shearing rate of $0.0066 \mathrm{~mm} / \mathrm{min}$. The second step was the triaxial creep test. The axial pressure at each level increased by a certain value until the deformation of the specimen under this pressure was stable (the axial displacement increment was less than $0.005 \mathrm{~mm} / \mathrm{d}$ ), and then the next level of axial pressure was applied until the specimen failed. For all the samples, the consolidation pressures (the net confining pressures $\sigma_{3}$ ) were 50,100, 200 and $300 \mathrm{kPa}$ and shear strain up to $20 \%$. Laboratory temperature was maintained at $23 \pm 1{ }^{\circ} \mathrm{C}$ by air-conditioner during test.

The detailed triaxial creep test steps are as follows: (1) Firstly, the specimens were saturated by vacuum extraction. After placing and sealing the specimen inside the triaxial chamber and taking measurements of diameter and height, the soil specimens were saturated from the top until a value of B (the pore-water parameter) was 0.95 $( \pm 0.02)$. (2) After completing the saturation process, the soil specimens were consolidated under a predetermined confining pressure, and pore water was allowed to drain out. The intervals of elapsed time and the corresponding volume change and pore water pressure were recorded. The consolidation process was allowed to continue until the pore water pressure dissipated by more than $95 \%$. (3) At the end of the consolidation, the axial load was increased to a specific value, and then grading loading was carried out until the specimen was destroyed. The loading diagram of the expansive soil sample is shown in Table 4, where deviator stress $q$ multiplied by cross-sectional area of the sample is the weight. The increment of the applied deviator stress was about $1 / 5-1 / 7$ of $q_{f}$ and if the axial deformation increment increased more dramatically under the pressure of this stage, the pressure increment applied by the next stage would be reduced. Besides, in order to compare the deformation development law with the same increment axial stress under different consolidation pressures, the pressure increment was $20 \mathrm{kPa}$ or $40 \mathrm{kPa}$ except for the last pressure level.

\section{Results and discussion}

\subsection{The relationship between axial strain and loading time}

In order to study the problem conveniently, it is assumed that the creep properties of expansive soils conform to the Boltzmann linear superposition principle [24], that is, the creep deformation of expansive soils can be obtained by summation of the deformation caused by the increment of the loads at all levels. The test data was processed using the Boltzmann superposition principle to obtain separate loading curves of expansive soils under different consolidation pressures. Fig. 3 is the separate loading creep curves of expansive soil samples under different consolidation pressures, and in the red box at upper right of consolidation pressures equal to $50,100,200 \mathrm{kPa}$ enlarges creep curves under lower deviator stress to show the pattern more clearly. Unfortunately, the apparatus was malfunctioned before the test of consolidation pressure equal to $300 \mathrm{kPa}$ was completed, and meanwhile, the same batch of samples had been used up, so that we failed to obtain the predetermined test data of deviator stress equal to $280 \mathrm{kPa}$. Fig. 4 shows the relationship between the increment of axial strain and deviator stress.

Table 4 The scheme of triaxial creep test

\begin{tabular}{ccc}
\hline$q_{f} / \mathrm{kPa}$ & $\sigma_{3} / \mathrm{kPa}$ & $q / \mathrm{kPa}$ \\
\hline 129.2 & 50 & $20 \rightarrow 40 \rightarrow 60 \rightarrow 80 \rightarrow 100 \rightarrow 110$ \\
183.5 & 100 & $40 \rightarrow 80 \rightarrow 120 \rightarrow 140$ \\
265.0 & 200 & $40 \rightarrow 80 \rightarrow 120 \rightarrow 160 \rightarrow 200$ \\
352.8 & 300 & $40 \rightarrow 80 \rightarrow 120 \rightarrow 160 \rightarrow 200 \rightarrow 240 \rightarrow 280$ \\
\hline
\end{tabular}




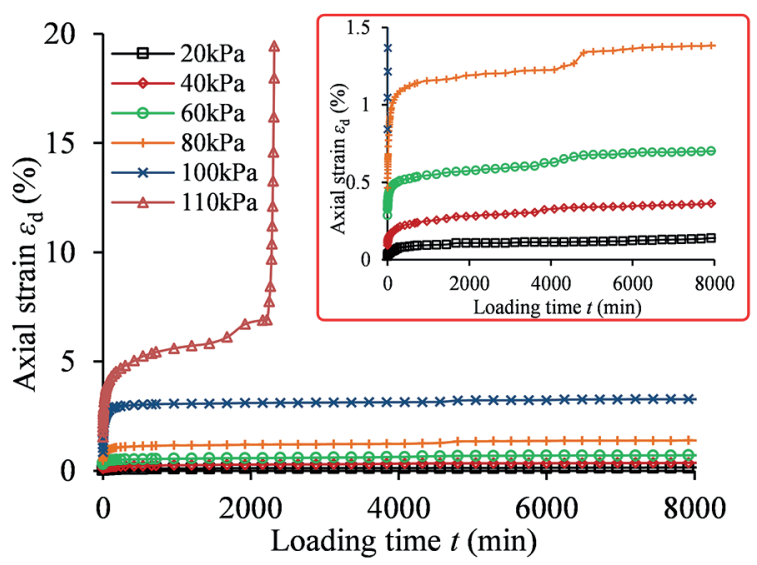

(a) $\sigma_{3}=50 \mathrm{kPa}$

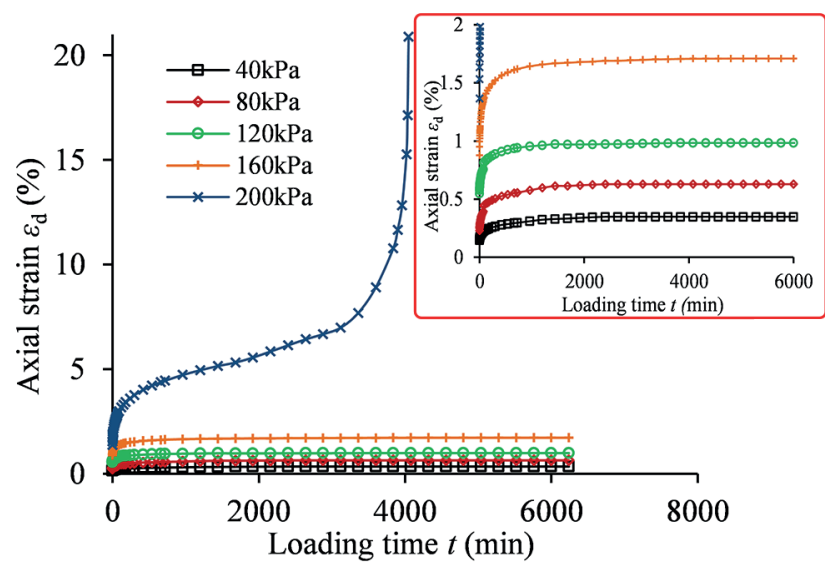

(c) $\sigma_{3}=200 \mathrm{kPa}$

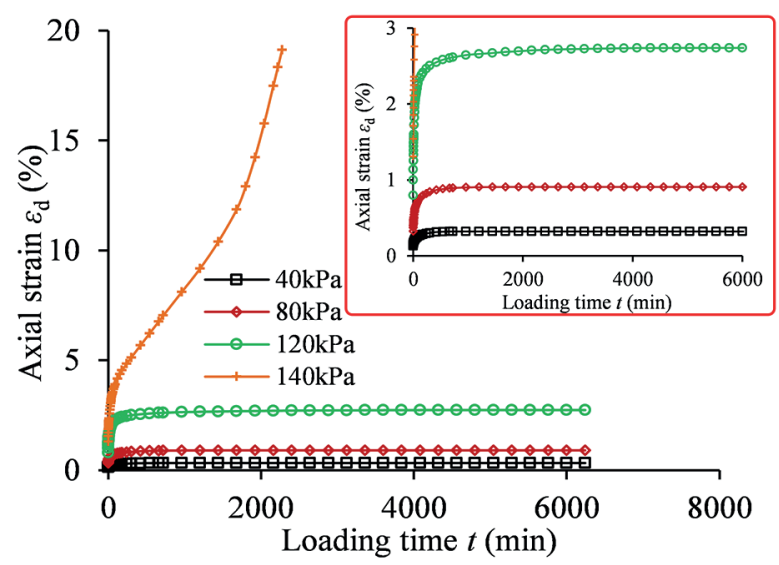

(b) $\sigma_{3}=100 \mathrm{kPa}$

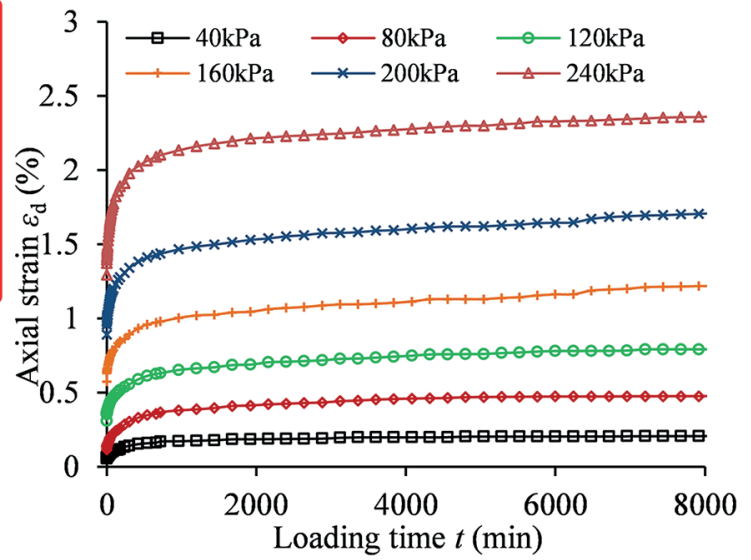

(d) $\sigma_{3}=300 \mathrm{kPa}$

Fig. 3 Relationship between axial strain and loading time

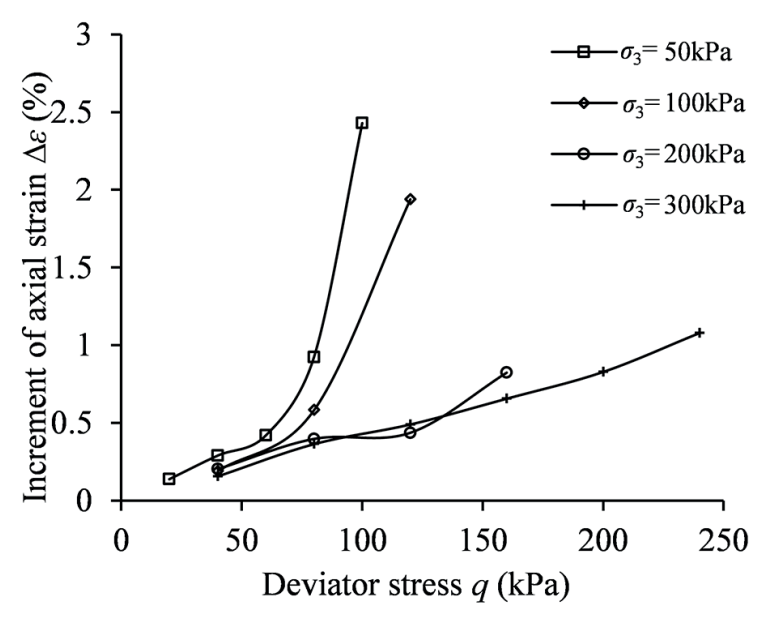

Fig. 4 Relationship between the increment of axial strain and deviator stress

It can be seen from Fig. 3 and Fig. 4 :

(1) During the grading incremental loading process, the expansive soil has small transient deformation under lower deviator stress levels. This is because the expansive soil is overconsolidated. With the loading time developing, the deformation tends to a stable value. When the consolidation pressure is the same, the lower the deviator stress level is, the shorter the time is needed to reach stable deformation, and the smaller the axial strain increment $\Delta \varepsilon_{d}$ is. For example, under consolidation pressure of $50 \mathrm{kPa}, \Delta \varepsilon_{d}$ are $0.14 \%, 0.29 \%, 0.42 \%, 0.92 \%$ and $2.43 \%$, respectively, at deviator stresses of 20, 40, 60, 80 and $100 \mathrm{kPa}$. Only decay creep occurs under lower deviator stress levels. Compared with the consolidated creep of expansive soil [18], the creep deformation under triaxial loading is considerable.

(2) With the increment of deviator stress, the deformation stable value of soil increases gradually, and $\Delta \varepsilon_{d}$ increases under each deviator stress level. $\Delta \varepsilon_{d}$ increases exponentially with increasing deviator stress, which shows that the expansive soil possesses nonlinear characteristics to some extent.

(3) Consolidation pressure has a great influence on creep behavior of expansive soils. The higher the consolidation pressure is, the larger the deviator stress level is needed for creep failure. When the consolidation pressures are 50, 
$100,200 \mathrm{kPa}$, the deviator stress levels required for creep failure of the expansive soil are 110,140 , and $200 \mathrm{kPa}$, respectively (as shown in Fig. 2 (a) (c)). It can be seen from Fig. 3 that under the same deviator stress, the greater the consolidation pressure is, the smaller the increment of axial strain is. For example, when the deviator stress is $40 \mathrm{kPa}$, the corresponding $\Delta \varepsilon_{d}$ are $0.29 \%, 0.19 \%, 0.20 \%$ and $0.16 \%$ under the consolidation pressures of 50,100 , 200 and $300 \mathrm{kPa}$, respectively. When the deviator stress is $80 \mathrm{kPa}$, the corresponding $\Delta \varepsilon_{d}$ are $0.92 \%, 0.58 \%, 0.40 \%$ and $0.36 \%$ under the consolidation pressures of 50,100 , 200 and $300 \mathrm{kPa}$, respectively.

(4) As the stress level increases to a certain level, the expansive soil gradually enters the accelerated creep process. It can be seen from Fig. 2 (a) (c), the accelerated creep stage of the expansive soil is short. Under consolidation pressure of $50,100,200 \mathrm{kPa}$, soil specimens are destroyed at deviator stress of 110,140 , and $200 \mathrm{kPa}$, respectively, and

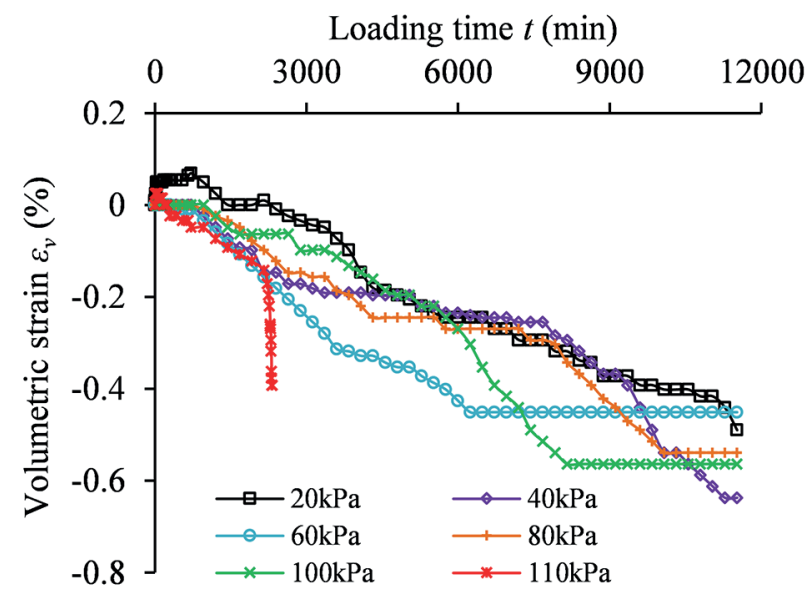

(a) $\sigma_{3}=50 \mathrm{kPa}$

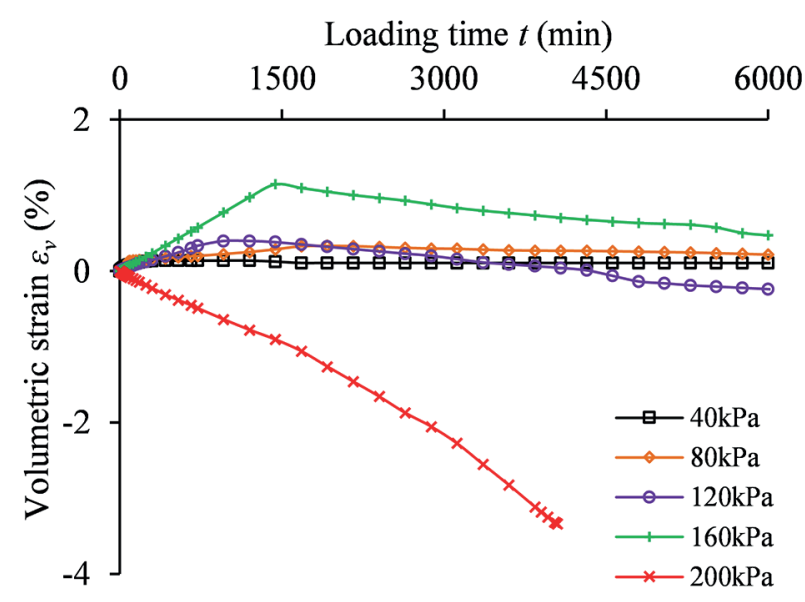

(c) $\sigma_{3}=200 \mathrm{kPa}$ it lasts 160,600 , and 450 min respectively from the occurrence of accelerated creep to the strain value of around $20 \%$. It can be seen from Fig. 2(a) that when the consolidation pressure is $50 \mathrm{kPa}$, the soil enters from the decay creep stage to the accelerated creep stage with the deviator stress increased by only $10 \mathrm{kPa}$ (from $100 \mathrm{kPa}$ to $110 \mathrm{kPa}$ ). Meanwhile, the deformation of the soil is relatively slow before destroyed, while the deformation increases sharply at about $2000 \mathrm{~min}$, which shows brittle failure characteristics. Compared with the whole creep process, the accelerated creep duration is very short, accounting for about $15 \%$ of the stress level acting duration on average.

\subsection{The relationship between volumetric strain and loading time}

Fig. 5 shows the curves of relationship between volumetric strain and loading time during the triaxial creep tests, and positive value represents the volume shrinkage.

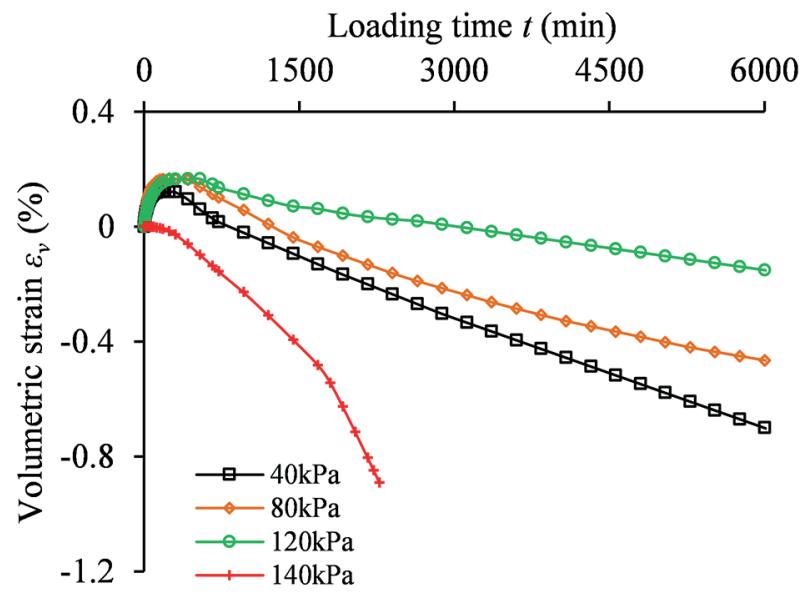

(b) $\sigma_{3}=100 \mathrm{kPa}$

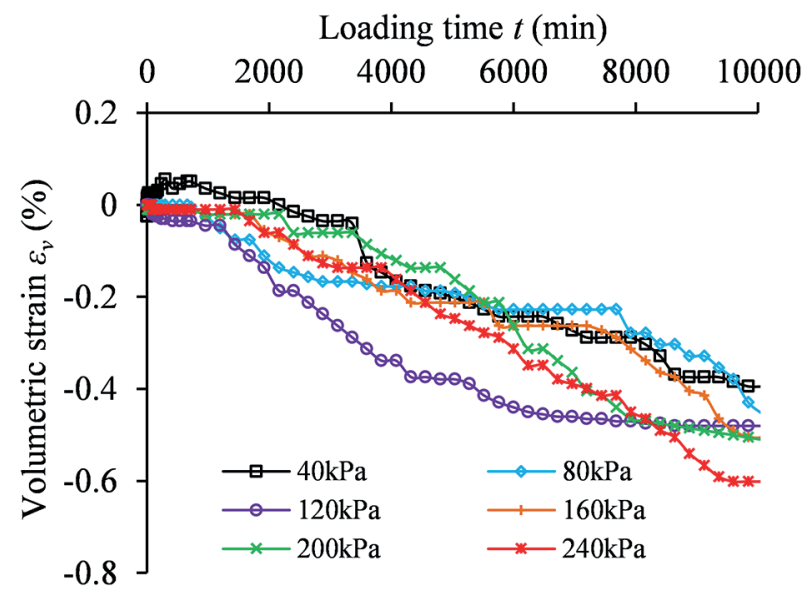

(d) $\sigma_{3}=300 \mathrm{kPa}$

Fig. 5 Relationship between volumetric strain and loading time 
It can be seen, in general, at the early stage of loading, it shows volume shrinkage with a small value. With the increase of loading time, the volumetric strain gradually develops from shear shrinkage to dilatancy, and the latter is predominated during the creep process. When entering the accelerated creep, the developing rate of volumetric strain increases sharply. That is because after loading for a period of time, the soil keeps absorbing water from the outside so that the volume expands. In general, shear shrinkage occurs during shearing for normally consolidated clays, while for overconsolidated clays, they are generally compressed first during the shear process and then exhibit dilatancy. Zhen et al. [25] analyzed the localization of deformation of an overconsolidated clay specimen by using finite element method. The numerical results showed that, different stress paths were seen inside and outside the shear band. The elements in the vicinities of the shear band took on volume shrinkage, dilatancy, and shrinkage due to being sucked, while the elements inside the shear band kept dilatant during shearing.

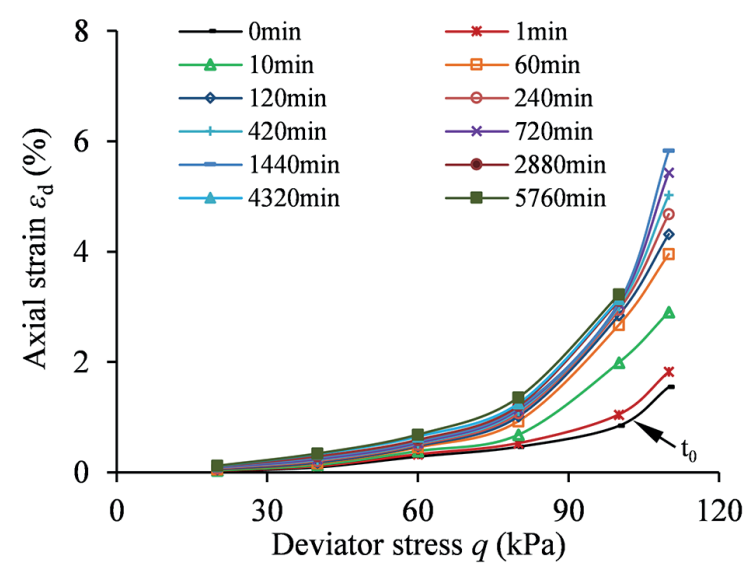

(a) $\sigma_{3}=50 \mathrm{kPa}$

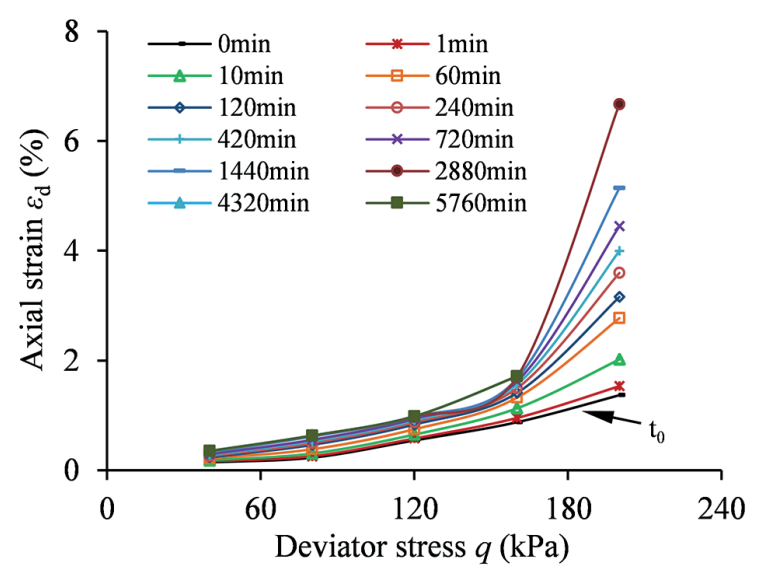

(c) $\sigma_{3}=200 \mathrm{kPa}$
According to the global volumetric strain change law of the expansive soil, when the deviator stress level is low, the strain is small, and obvious shear zone has not been formed. The volumetric strain change is similar to the element outside the shear band, which goes through the process of volume shrinkage and dilatancy. While deviator stress level is high, the strain gradually increases, and soil shear band develops and gradually coalesces. For the big dilatancy quantity and strong water absorption of element inside the shear band, the migration rate of moisture from the outside of shear band to the inside of that keeps increasing, and the soil outside the shear band keeps absorbing water from the outside, which is reflected in the global dilatancy rate increasing.

\subsection{Isochronous stress-strain curves}

The isochronous stress - strain curves of expansive soils can be obtained based on the creep test data, as shown in Fig. 6. It can be seen that, with the creep time passing, the isochronous stress - strain curves are gradually bending

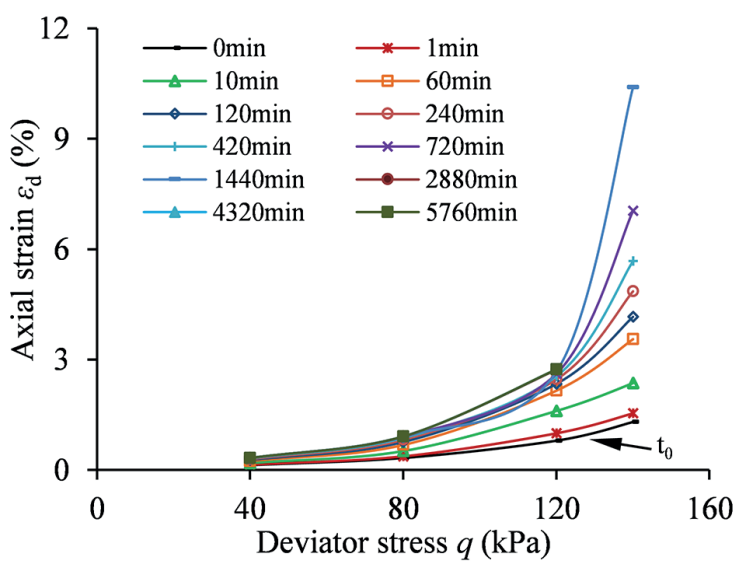

(b) $\sigma_{3}=100 \mathrm{kPa}$

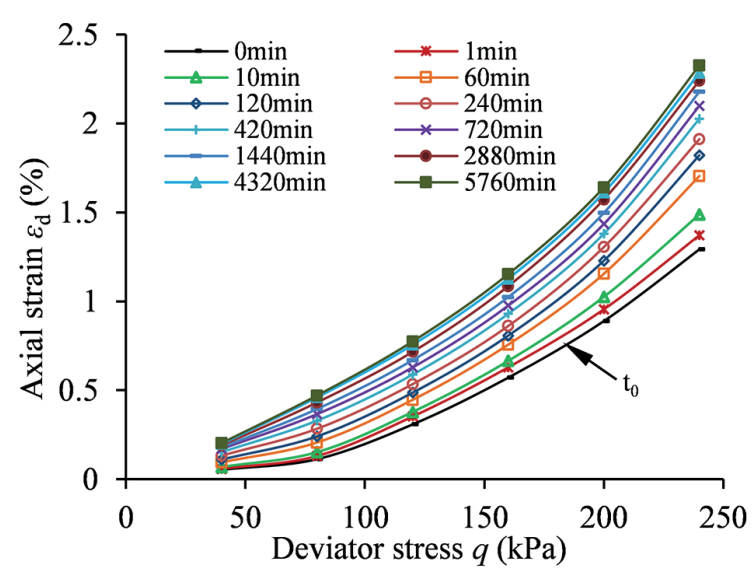

(d) $\sigma_{3}=300 \mathrm{kPa}$

Fig. 6 Isochronous stress-strain curves of expansive soils 
from the deviator stress axis to strain axis, and the longer the creep time is, the more significant the isochronous curve deviates from the straight line. Besides, at a certain moment, the bending degree of the isochronous stressstrain curve is also related to the deviator stress level, and the higher the deviator stress level is, the greater the degree of curves bends toward the strain axis. Therefore, we can conclude that the expansive soil has nonlinear creep characteristics, and the nonlinear degree is concerned to the creep duration and deviator stress level. The linear range decreases with the creep time and stress level increasing, and the degree of nonlinearity increases accordingly.

\section{Nonlinear empirical creep model of expansive soils 4.1 Establishment of nonlinear creep model}

The empirical functions commonly used to describe nonlinear creep characteristics of soils include power function, hyperbolic function, logarithmic function, exponential function and polynomial function. The mostly widely used empirical models are Singh-Mitchell model [21] and Mesri model [22]. However, Singh-Mitchell model may not well describe the stress-strain curves in the range of all deviator stress levels, while Mesri model can describe the creep behavior of soils under arbitrary loading level, but the effect is not ideal.

Zang [26] proposed an empirical formula to describe the cyclic accumulated deformation of clay under cyclic load, based on the cyclic accumulated deformation law of clay, that is

$$
\varepsilon=\lambda\left(\delta^{N}-1\right)+\frac{b N^{m}}{1+c N^{m}},
$$

where $\varepsilon$ is the accumulative deformation; $N$ is the cycle times; $\lambda, b, c, m$ and $\delta$ are parameters related to stress conditions and soil properties. When $\delta>1$, this equation can describe the accelerating strain, while $0<\delta<1$, it can describe the stable strain.

As shown in Fig. 7, it is difficult to describe the whole creep curve with only exponential function and hyperbolic function, while Eq. (1) can well describe the creep characteristics of soils at various stages by superposition of exponential function and hyperbolic function.

The soil deformation develops with cyclic cycles increasing under dynamic cyclic load, which is essentially the same to soil creep test that the soil deformation develops with time under static load. In Eq. (1), when $N=0, \varepsilon$ is zero. However, according to the creep curve (Fig. 3), transient deformation of expansive soils occurs at the moment when

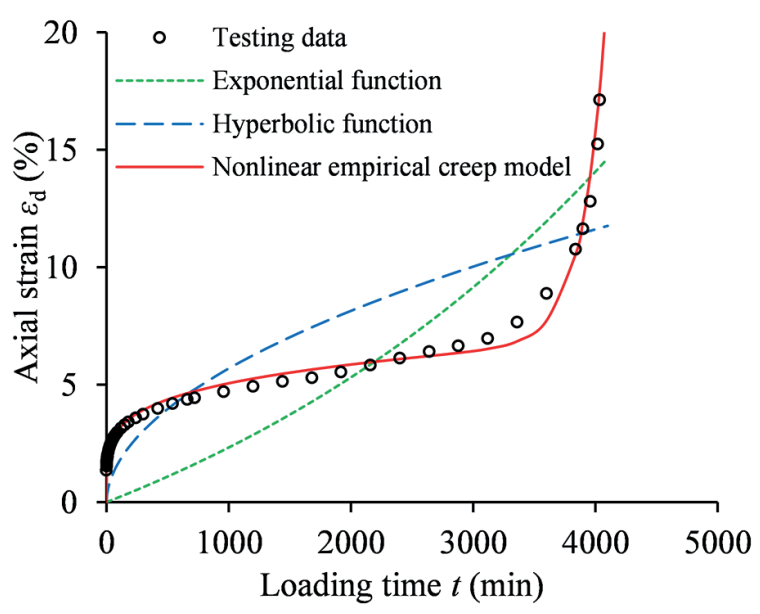

Fig. 7 Curve fitting to creep test data by different functions

load is applied. In other words, when $t=0, \varepsilon$ is not zero, but a constant. Therefore, by referring to Eq. (1) and improving it, the nonlinear empirical creep model is obtained as shown in Eq. (2). When $t=0, \varepsilon_{\mathrm{d}}=A$. Thus $A>0$ which indicates that the soil deformation occurs at the moment the load is applied.

$\varepsilon_{\mathrm{d}}=A \eta^{t}+\frac{B t^{M}}{1+C t^{M}}$,

where $\varepsilon_{\mathrm{d}}$ is the axial strain; $t$ is the creep duration under a certain load level; $A, B, C, M$ and $\eta$ are parameters related to stress conditions and soil properties. When $\eta>1$, this equation can describe the accelerated creep process; while $0<\eta<1$, it can describe the stable creep process.

\subsection{Suitability analysis of the nonlinear creep model}

Curve-fitting method is a widely used method to determine the parameters of rheological model of rock and soil. Based on the results of triaxial creep test of expansive soils and the basic principle of least square method, this paper adopts curve-fitting method to fit the test data. Fig. 8 shows the comparison of creep test curves and fitting curves under different deviator stress levels under consolidation pressures of 50, 100, 200 and $300 \mathrm{kPa}$. It can be seen that the fitting curves of the nonlinear creep model are in good agreement with the test points. The correlation coefficients of most fitting curves are above 0.97 , which indicates that the model can describe the creep characteristics of expansive soils well and has certain applicability.

\section{Identification of critical failure stress based on nonlinear empirical creep model}

The curve fitting results show that when the consolidation pressure is a constant, the parameter $\eta$ that represents 


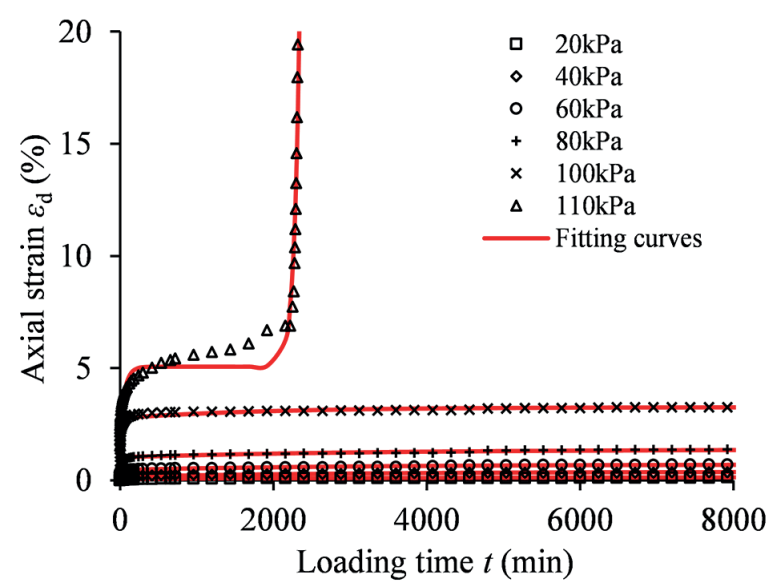

(a) $\sigma_{3}=50 \mathrm{kPa}$

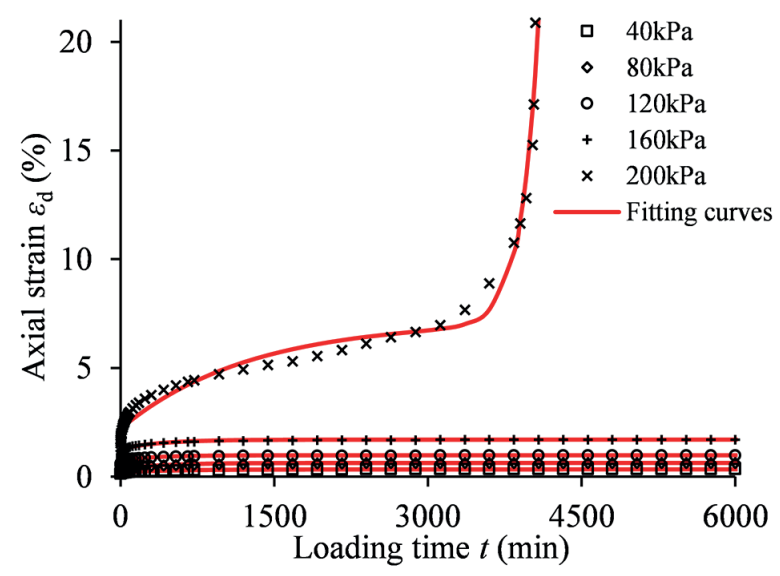

(c) $\sigma_{3}=200 \mathrm{kPa}$

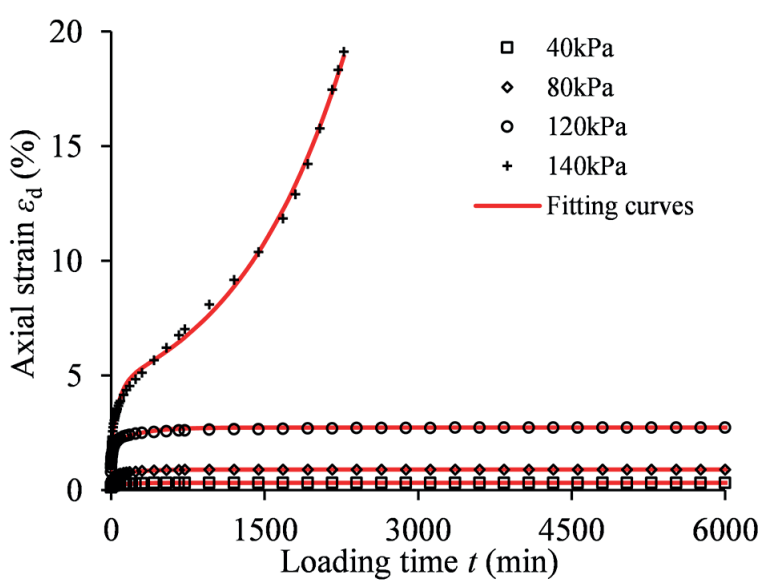

(b) $\sigma_{3}=100 \mathrm{kPa}$

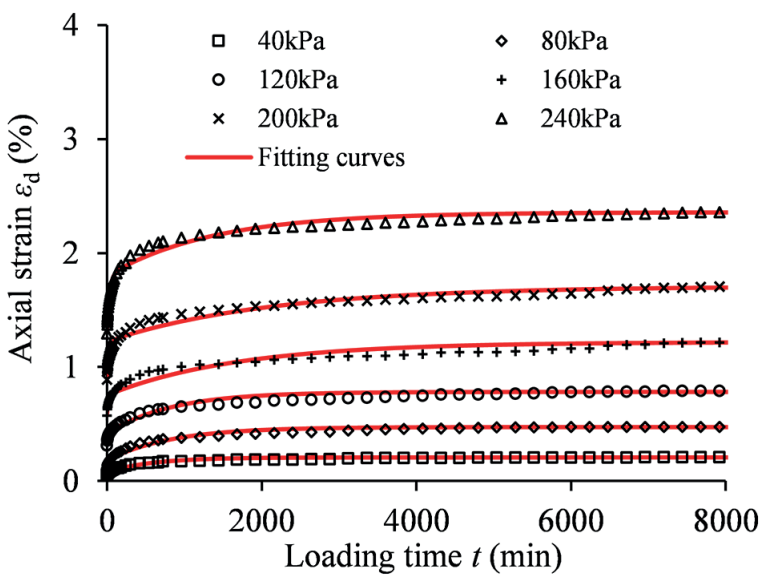

(d) $\sigma_{3}=300 \mathrm{kPa}$

Fig. 8 Test data and fitting curves of creep test

the nonlinear effect increases with the increase of deviator stress. As mentioned above, in the nonlinear empirical creep model, $\eta>1$ reflects the accelerated creep process that the soil deformation develops rapidly and the failure occurs, while $0<\eta<1$ reflects the stable creep process that the strain tends to be stable with time. Therefore, the stress corresponding to the deformation of the soil between the stable state and the failure state is the critical failure stress, where $\eta=1$.

Fig. 9 shows the relationship between parameter $\eta$ and deviator stress in the nonlinear empirical creep model. It can be seen that the parameter $\eta$ has a good linear relationship with the applied deviator stress level under the same consolidation pressure. At lower consolidation pressures of 50 and $100 \mathrm{kPa}$, the curves almost coincide; as the consolidation pressure increases, the curves are closer to the axis of deviator stress, and the curves are almost parallel. Through the linear relationship between parameter $\eta$ and deviator stress, the stress corresponding to $\eta=1$ is

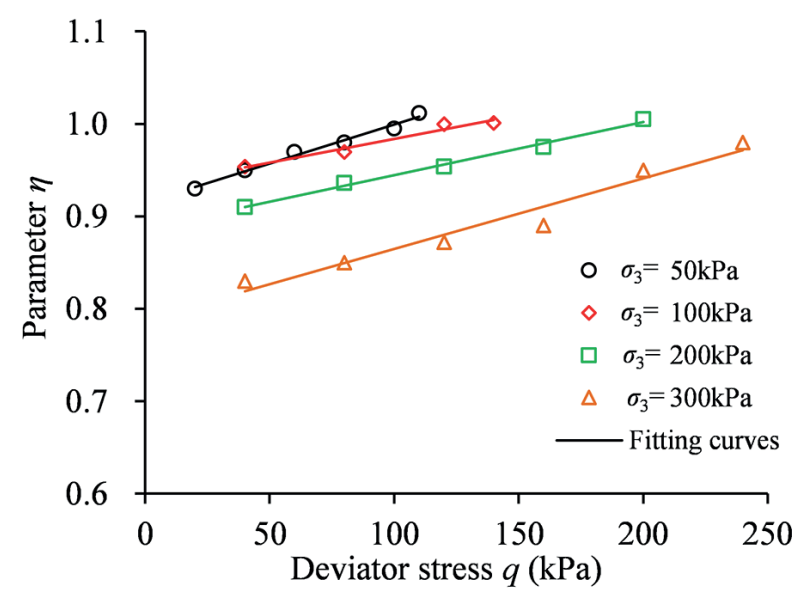

Fig. 9 Relationship between parameter $\eta$ and deviator stress

the critical failure stress. Table 5 gives the critical failure stress of the expansive soils under different consolidation pressures, as well as the corresponding shear failure stress under conventional triaxial test and the ratio between them. It can be seen that the ratio of the critical 
Table 5 Critical failure stress

\begin{tabular}{lccc}
\hline$\sigma^{3} / \mathrm{kPa}$ & $q_{f} / \mathrm{kPa}$ & critical failure stress $\sigma_{s} / \mathrm{kPa}$ & $\sigma_{s} / q_{f}$ \\
\hline 50 & 129.2 & 100.5 & 0.7779 \\
100 & 183.5 & 131.6 & 0.7172 \\
200 & 265.0 & 196.5 & 0.7415 \\
300 & 352.8 & 277.2 & 0.7857 \\
\hline
\end{tabular}

failure stress to conventional shear failure stress ranges from $70 \%$ to $80 \%$, with average of $75.56 \%$. Therefore, the critical failure stress of expansive soils can be estimated by the $q_{f}$ value of that obtained from conventional triaxial shear tests, i.e., $75.56 \%$ of $q_{f}$ can be used to estimate the critical failure stress with an error of $5.5 \%$.

\section{Conclusions}

In the present study the evolution law of axial strain and volumetric strain with loading time under constant pressure was studied on the modified stress-controlled triaxial apparatus, and a nonlinear empirical creep model with good universality was established to describe the creep characteristics of expansive soils under triaxial stress. Creep tests under 4 consolidation pressures were carried out to study the creep characteristics of expansive soils, and the time period for each of the creep test varied from a minimum of around 15 days to a maximum of around 42 days. The following conclusions are made based on the observed results:

(1) The creep tests of expansive soils show that under lower deviator stress, only instantaneous deformation and decay creep occur, and the axial strain increment increases exponentially with the increase of the deviator stress level. While deviator stress reaches a certain value, attenuation creep, steady creep and accelerated creep all occur in a creep curve.

(2) The isochronous stress - strain curves show that the expansive soil has nonlinear creep characteristics, and

\section{References}

[1] Bao, C. G. "非饱和土的性状及膨胀土边坡稳定问题" (Behavior of unsaturated soil and stability of expansive soil slope), Chinese Journal of Geotechnical Engineering, 26(1), pp. 1-15, 2004. (in Chinese)

https://doi.org/10.3321/j.issn:1000-4548.2004.01.001

[2] Hu, X. L., Sun, M. J., Tang, H. M., Xie, N., Guo, J. "三峡库区马 家沟滑坡滑体粗粒土蠕变试验研究" (Creep tests of gravel-soil of Majiagou landslide in Three Gorges Reservoir area), Rock and Soil Mechanics, 35(11), pp. 3163-3169, 2014. (in Chinese) https://doi.org/10.16285/j.rsm.2014.11.028 the nonlinear degree is related to the creep duration and stress level. The linear range decreases with the creep time and stress level increasing, and the degree of nonlinearity increases accordingly.

(3) At the initial stage of loading, the volumetric strain exhibits shear shrinkage with a small value. With the extension of loading time, the volumetric strain gradually varies from shear shrinkage to dilatancy. When entering the accelerated creep stage, the developing rate of volumetric strain increases sharply. That is, the soil outside the shear band keeps absorbing water from the outside after loading for some time.

(4) A nonlinear creep model is proposed based on the empirical formula of cyclic accumulation deformation of clay. The fitting curves of the nonlinear creep model are in good agreement with the test data, which shows that the model can describe the creep characteristics of expansive soils well.

(5) The critical failure stress of expansive soils can be obtained according to the nonlinear creep model, and the critical failure stress is about $75.56 \%$ of the shear failure stress. Therefore, the critical failure stress of creep can be estimated according to the triaxial shear test.

The above conclusions are arrived based on expansive soils selected in Nanyang Basin, Henan province, China. Therefore, these conclusions need verification through other expansive soils for better understanding. In addition, further studies are needed to ascertain the creep performance of expansive soils under different stress paths.

\section{Acknowledgement}

The project presented in this article is supported by the National Natural Science Foundation of China (no. 12002121, 41430634) and Science and Technology Innovation Team Foundation of Hubei Province Education Department (T201823).

[3] Wang, X., Wang, J., Zhan, H., Li, P., Qiu, H., Hu, S. "Moisture content effect on the creep behavior of loess for the catastrophic Baqiao landslide", Catena, 187, Article number: 104371, 2020. https://doi.org/10.1016/j.catena.2019.104371

[4] Xie, X., Qi, S. W., Zhao, F., Wang, D. H. "Creep behavior and the microstructural evolution of loess-like soil from Xi'an area, China", Engineering Geology, 236, pp. 43-59, 2018. https://doi.org/10.1016/j.enggeo.2017.11.003

[5] Zhou, Z., Ma, W., Zhang, S., Du, H., Mu, Y., Li, G. "Multiaxial creep of frozen loess", Mechanics of Materials, 95, pp. 172-191, 2016. https://doi.org/10.1016/j.mechmat.2015.11.020 
[6] He, S.-H., Ding, Z., Xia, T.-D., Zhou, W.-H., Gan, X.-L., Chen, Y.-Z., Xia, F. "Long-term behaviour and degradation of calcareous sand under cyclic loading", Engineering Geology, 276, Article number: 105756, 2020.

https://doi.org/10.1016/j.enggeo.2020.105756

[7] Ye, J. H., Cao, M., Li, G. "中国南海吹填岛礁原状钻质砂蠕变 特征初探" (Preliminary study on the creep characteristics of calcareous sand from reclaimed coral reef islands in south China sea), Chinese Journal of Rock Mechanics and Engineering, 38(6), 12421251, 2019. (in Chinese)

https://doi.org/10.13722/j.cnki.jrme.2018.0695

[8] Feng, W.-Q., Lalit, B., Yin, Z.-Y., Yin, J.-H. "Long-term non-linear creep and swelling behavior of Hong Kong marine deposits in oedometer condition", Computers and Geotechnics, 84, pp. 1-15, 2017.

https://doi.org/10.1016/j.compgeo.2016.11.009

[9] Li, D., Zhang, C., Ding, G., Zhang, H., Chen, J., Cui, H., Pei, W., Wang, S., An, L., Li, P., Yuan, C. "Fractional derivative-based creep constitutive model of deep artificial frozen soil", Cold Regions Science and Technology, 170, Article number: 102942, 2020. https://doi.org/10.1016/j.coldregions.2019.102942

[10] Wang, P., Liu, E., Song, B., Liu, X., Zhang, G., Zhang, D. "Binary medium creep constitutive model for frozen soils based on homogenization theory", Cold Regions Science and Technology, 162, pp. $35-42,2019$.

https://doi.org/10.1016/j.coldregions.2019.03.019

[11] Hou, F., Lai, Y. M., Liu, E. L., Luo, H. W., Liu, X. Y. "A creep constitutive model for frozen soils with different contents of coarse grains", Cold Regions Science and Technology, 145, pp. 119-126, 2018. https://doi.org/10.1016/j.coldregions.2017.10.013

[12] Li, D., Yang, X., Chen, J. "A study of Triaxial creep test and yield criterion of artificial frozen soil under unloading stress paths", Cold Regions Science and Technology, 141, pp. 163-170, 2017. https://doi.org/10.1016/j.coldregions.2017.06.009

[13] Xiang, G., Yin, D., Cao, C., Gao, Y. "Creep modelling of soft soil based on the fractional flow rule: Simulation and parameter study", Applied Mathematics and Computation, 403, Article number: 126190, 2021.

https://doi.org/10.1016/j.amc.2021.126190

[14] Feng, W.-Q., Yin, J.-H., Chen, W.-B., Tan, D.-Y., Wu, P.-C. "A new simplified method for calculating consolidation settlement of multi-layer soft soils with creep under multi-stage ramp loading", Engineering Geology, 264, Article number: 105322, 2020. https://doi.org/10.1016/j.enggeo.2019.105322

[15] Venda Oliveira, P. J., Santos, S. L., Correia, A. A. S., Lemos, L. J. L. "Numerical prediction of the creep behaviour of an embankment built on soft soils subjected to preloading", Computers and Geotechnics, 114, Article number: 103140, 2019.

https://doi.org/10.1016/j.compgeo.2019.103140
[16] Zhou, W.-H., Tan, F., Yuen, K.-V. "Model updating and uncertainty analysis for creep behavior of soft soil", Computers and Geotechnics, 100, pp. 135-143, 2018.

https://doi.org/10.1016/j.compgeo.2018.04.006

[17] Sivasithamparam, N., Karstunen, M., Bonnier, P. "Modelling creep behaviour of anisotropic soft soils", Computers and Geotechnics, 69, pp. 46-57, 2015. https://doi.org/10.1016/j.compgeo.2015.04.015

[18] Li, Z. Y., Xiao, H. B., Jin, W. T., Yi, W. "南宁膨胀土非线性流变模 型研究" (Study of nonlinear rheological model of Nanning expansive soils), Rock and Soil Mechanics, 33(8), pp. 2297-2302, 2012. (in Chinese) https://doi.org/10.3969/j.issn.1000-7598.2012.08.010

[19] Xu, H., Xiao, H. B., Teng, K. "南宁膨胀土直剪蠕变特性及长期强 度试验研究" (Experimental study on direct shear creep characteristics and long-term strength for Nanning expansive soil), Highway Engineering, 36(1), pp. 31-36, 2011. (in Chinese) https://doi.org/10.3969/j.issn.1674-0610.2011.01.009

[20] Ning, X. L., Xiao, H. B., Zhang, C. X., He, B., Xie, J. Y. "膨胀土非 线性蠕变模型研究" (Study on the nonlinear creep model of expansive soil), Journal of Natural Disasters, 26(1), pp. 149-155, 2017. (in Chinese) https://doi.org/10.13577/j.jnd.2017.0118

[21] Singh, A., Mitchell, J. K. "General stress-strain-time function for soils", Journal of the Soil Mechanics and Foundations Division, 94(SM1), pp. 21-46, 1968. https://doi.org/10.1061/JSFEAQ.0001084

[22] Mesri, G., Febres-Cordero, E., Shields, D. R., Castro, A. "Shear stress-strain-time behaviours of clay", Geotechnique, 31(4), pp. 537-552, 1981.

https://doi.org/10.1680/geot.1981.31.4.537

[23] Li, G., Zhang, J. L., Yang, Q., Jiang, M. J. "海陆交互相黏性土 蠕变试验与经验模型研究" (Creep test on the sea - land interaction clay and its empirical model), Journal of Dalian University of Technology, 58(1), pp. 64-71, 2018. (in Chinese) https://doi.org/10.7511/dllgxb201801010

[24] Hou, J., Guo, Z., Li, J., Zhao, L. "Study on triaxial creep test and theoretical model of cemented gangue-fly ash backfill under seepage-stress coupling", Construction and Building Materials, 273, Article number: 121722, 2021. https://doi.org/10.1016/j.conbuildmat.2020.121722

[25] Zhen, W. Z., Sun, D. A., Duan, B. "不同应力路径下超固结黏土试 样变形局部化分析" (Analysis of strain localization in overconsolidated clay specimens along different stress paths), Rock and Soil Mechanics, 32(1), pp. 293-298, 2011. (in Chinese) https://doi.org/10.3969/j.issn.1000-7598.2011.01.046

[26] Zang, M. Kong, L. W., Cao, Y. "描述循环荷载作用下黏土累积 变形的改进模型" (An improved model for cumulative deformations of clay subjected to cyclic loading), Rock and Soil Mechanics, 38(2), pp. 435-442, 2017. (in Chinese) https://doi.org/10.16285/j.rsm.2017.02.017 